\title{
Política de saúde e HIV: direito à saúde e reformas regressivas
}

\author{
Health policy and HIV. The right to healthcare and regressive reforms
}

\section{Ana Cristina de Souza VIEIRA*}

Resumo: $\mathrm{O}$ artigo discute a política de saúde brasileira e as reformas regressivas que a afetam. Destaca medidas que acentuam a fragilidade do financiamento, desde a criação do Sistema Único de Saúde (SUS), intensificadas sob o governo de Michel Temer, iniciado em 2016. Expõe a realidade do HIV no Brasil e as diretrizes de enfrentamento da aids, confrontando as necessidades das pessoas que vivem com HIV e a política de saúde para a doença. Considera-se que o caráter universalista e progressivo da política de saúde, desde sua aprovação na Constituição de 1988, vem sendo submetido a interesses de mercadorização da saúde. As reformas regressivas nessa política, com corte de recursos, incidirão sobre a política de saúde das pessoas com HIV, restringindo seu direito à saúde. A partir de uma leitura crítico-dialética da realidade, bibliografia e dados secundários foram utilizados para apoiar as reflexões.

Palavras-chave: Política de saúde. Privatização da saúde. Saúde e reformas regressivas.

Abstract: The paper discusses Brazilian health policy and the regressive reforms that affect it. It highlights measures that accentuate the fragility of funding since the creation of the National Health System (SUS) and that have intensified, since 2016, under the government of Michel Temer. It exposes the reality of HIV in Brazil and the guidelines for coping with AIDS, addresses the needs of people who live with HIV and the health policies related to the illness. The paper considers that the universal and progressive character of health policy has, since its adoption in the 1988 Constitution, been subjected to the marketisation of health. Regressive reforms of this policy, with cuts in resources, will restrict the right to healthcare of people living with HIV. A critical-dialectical reading of reality, literature and secondary data were used to support the reflections.

Keywords: Health policy. Privatisation of health. Health and regressive reforms.

Submetido em: 29/12/2017. Revisado em: 19/2/2018. Aceito em: 28/2/2018.

\section{INTRODUÇÃO}

preocupação com a política de saúde para enfrentamento do HIV tem exigido uma A reflexão sobre a orientação neoliberal do Estado brasileiro e sobre o caráter regressivo do sistema tributário nacional, na perspectiva de entender o Sistema Único de Saúde (SUS) nessa conjuntura e a possibilidade de responder às necessidades em saúde das pessoas vivendo com HIV. O artigo discute, portanto, a política de saúde brasileira e as reformas regressivas que a afetam. Destaca medidas que vêm sendo implementadas desde a criação do SUS, minando seu financiamento e restringindo-o. No governo de Michel Temer, iniciado em 2016, mais cortes nas políticas sociais vão recair sobre o SUS, reduzindo sua resolutividade. A partir de um leitura crítico-dialética, no artigo foi utilizada bibliografia sobre o

\footnotetext{
* Assistente social. Doutora em Serviço Social pela Pontifícia Universidade Católica de São Paulo (PUC-SP). Professora Titular da Graduação e Pós-Graduação em Serviço Social da Universidade Federal de Pernambuco (UFPE). Avenida Prof. Moraes Rego 1235, Cidade Universitária, Recife (PE), CEP 50670-901. Pesquisadora 1B do Conselho Nacional de Desenvolvimento Científico e Tecnológico. E-mail: <anacvieira12@gmail.com>. ORC ID: < http://orcid.org/oooo-0002-8844-5375>.
}

Argum., Vitória, v. 10, n.1, p. 72-83, jan./abr. 2018. 
regressivo sistema tributário brasileiro, o SUS e a política de saúde para HIV com as diretrizes de enfrentamento da aids. Analisam-se dados secundários sobre as dimensões atuais do HIV no Brasil, destacando-se algumas tendências que expõem a necessidade de garantir serviços de saúde para reduzir o impacto da epidemia. Considera-se que o caráter universalista e progressivo da política de saúde, desde sua aprovação na Constituição de 1988, vem sendo submetido a interesses de mercadorização da saúde, e as reformas regressivas nessa política, com corte de recursos, incidirão sobre as pessoas com HIV, restringindo seu direito à saúde.

\section{SISTEMA TRIBUTÁRIO BRASILEIRO REGRESSIVO E POLÍTICA DE SAÚDE}

O direito à saúde, por muito tempo, não fez parte da vida dos brasileiros. A assistência à saúde no país só passou a ser objeto de ação do Estado a partir das primeiras décadas do século XX, predominando ações públicas coletivas diante de epidemias. A assistência em saúde para trabalhadores assalariados tinha caráter contributivo, enquanto os demais cidadãos recorriam a instituições filantrópicas em suas necessidades de saúde.

A criação do SUS pela Constituição de 1988 e sua regulamentação pelas Leis 8.08o e 8.142 em 1990 representam uma mudança radical em relação ao padrão de atenção à saúde, instaurando a perspectiva de direito universal à saúde, como dever do Estado, sem exigência de pagamento, com integralidade e qualidade. Sua criação respondeu ao Movimento de Reforma Sanitária, aos anseios de diferentes segmentos da população brasileira por democratização e por direitos sociais.

Em sua criação, havia a previsão de seu financiamento através dos Orçamentos da Seguridade Social (OSS), da União, dos estados e dos municípios, além de outras fontes. Mas, desde aquele momento, o SUS já convivia com interesses privados contrários à sua concretização: de empresas médicas, farmacêuticas, empreendimentos hospitalares, de todos os segmentos que se beneficiavam com a venda de serviços de saúde ao setor público, com recursos públicos recebidos a fundo perdido para a construção de hospitais, com a compra de equipamentos para realização de exames de média e alta complexidade.

As políticas sociais implementadas pelo Estado, entre elas a de saúde, supõem, portanto, seu financiamento através de recursos públicos arrecadados pelo sistema tributário brasileiro. Este, ao longo das últimas décadas, ganhou a marca da regressividade, em contraposição à Constituição de 1988, que traz, segundo Salvador:

[...] os princípios constitucionais basilares da justiça fiscal: equidade, capacidade contributiva e progressividade. A tributação é um dos melhores instrumentos para erradicar a pobreza e reduzir as desigualdades sociais, objetivos essenciais da República, tal como definidos na Constituição de 1988 (SALVADOR, 2016, p. 6o).

Entretanto, a legislação infraconstitucional, elaborada a partir de 1995, a partir do governo de Fernando Henrique Cardoso (1995-2002), vem corroendo os princípios constitucionais, gerando distorções que aprofundaram a regressividade do sistema tributário. Entre as medidas tomadas, estão:

A isenção de imposto de renda na distribuição de lucros a pessoas físicas, eliminando o imposto na fonte sobre lucros e dividendos distribuídos para os resultados apurados

Argum., Vitória, v. 10, n.1, p. 72-87, jan./abr. 2018. 
a partir de $1^{\text {o }}$ de janeiro de 1996; b) instituição dos 'juros sobre capital próprio', que [...] significa uma redução da base tributária do imposto de renda e da contribuição social do lucro líquido, além de ser uma forma secundária de distribuição de lucros e dividendos (Lei n $9.249 / 95$, art. 9o); c) eliminação da alíquota de $35 \%$ do imposto de renda de pessoa física, reduzindo a progressividade desse imposto (Lei $\left.\mathrm{n}^{\circ} 9.250 / 95\right)$; e) elevação da alíquota do imposto de renda de pessoa física, de $25 \%$ para $27,5 \%$ (Lei ${ }^{\circ}$ 9.532/97, art. 11ㅇ); f) aumento do número de declarantes do imposto de renda, pois a tabela desse imposto deixou de ser corrigida (1996 a 2001), fazendo com o que os trabalhadores de mais baixa renda passassem a ser tributados (Lei no 9.430/96); g) redução para zero das alíquotas de imposto de renda e de CPMF para investidores estrangeiros no Brasil, garantida pela medida provisória no 281 (15/02/2006). [...] Os grandes beneficiados pela medida foram os bancos; h) significativas alterações no tratamento tributário das aplicações financeiras (Lei $\mathrm{n}^{\circ} 11.033$, de 21/12/2004), favorecendo os aplicadores no mercado financeiro e na bolsa de valores (SALVADOR, 2016, p. 61).

A regressividade do sistema tributário onera trabalhadores e a população mais pobre, pois, além da tributação prioritária dos rendimentos originários do trabalho, é tributado o consumo:

\begin{abstract}
A carga tributária bruta, incluindo a arrecadação da União, estados, Distrito Federal e municípios, aumentou significativamente entre 1995 e 2004, passando de $27 \%$ para $33 \%$ do PIB. Mas nosso sistema está concentrado em tributos regressivos e indiretos, justamente os que oneram mais os trabalhadores e os pobres. Mais da metade da arrecadação provém de tributos que incidem sobre bens e serviços, com baixa tributação sobre renda e patrimônio (SILVEIRA et al., 2008 apud SALVADOR, 2016, p. 62-63).
\end{abstract}

O SUS indicava, em sua concepção, a possibilidade de se instaurar uma política de caráter progressivo, segundo Ocké-Reis (2016, não paginado): "Priorizar o financiamento do SUS é entender o sistema como um motor de desenvolvimento e de combate à desigualdade, uma vez que o SUS desconcentra a renda”. Esse potencial progressivo do SUS, na medida em que o sistema tributário que gera os recursos para seu funcionamento se apoia em impostos regressivos, se restringe e os custos recaem, principalmente, sobre os trabalhadores de menor renda.

Além disso, como afirma Bahia (2016):

O ponto comum a todos os governos posteriores à Constituição de 1988 é o subfinanciamento do SUS e a liberação de transferências, diretas e indiretas, sob a forma de subsídios e deduções fiscais, para empresas privadas que comercializam planos e assistência à saúde. Tirar com uma mão do SUS e dar com a outra ao setor privado tornou-se uma prática permanente dos governos federais (BAHIA, 2016, p. 53).

Algumas medidas na área de saúde vêm minando o financiamento do SUS desde os anos 90, limitando o direito à saúde. A primeira delas foi o descumprimento da destinação de 30\% do orçamento da seguridade social, constitucionalmente indicada para o SUS. A esta medida seguiram-se outras, apontadas por Santos (2015): retirada do Fundo Previdenciário da base de cálculo da parcela federal; ampliação dos subsídios ao mercado, com o cofinanciamento público de planos privados para servidores e empregados públicos; ampliação da renúncia fiscal para pessoas físicas no âmbito da assistência; desvio da Contribuição Provisória sobre a Movimentação Financeira (CPMF) para outros dispêndios da União, a partir de 1996; criação das Organizações Sociais (OS) em 1998 e das Organizações da Sociedade Civil de Interesse Público

Argum., Vitória, v. 10, n.1, p. 72-87, jan./abr. 2018. 
(Oscips) em 200o, organizações privadas sem fins lucrativos, para gerenciar unidades de saúde; aprovação da Lei da Responsabilidade Fiscal (LRF) em 2000, restringindo a contratação de servidores públicos.

Somente em 2000, foi aprovada a Emenda Constitucional 29, que define diretrizes para financiamento do SUS, entretanto, sem a delimitação de percentual mínimo de gastos federais (BRASIL, 2000). Entretanto, essa emenda só foi regulamentada em 2012, expondo a dificuldade de negociar o financiamento da saúde. Em 2014, outro golpe foi aplicado ao SUS: a aprovação da Medida Provisória 656 (BRASIL, 2014), que legaliza a abertura de toda a estrutura assistencial privada à aquisição pelo capital estrangeiro. Esta medida foi transformada na Lei 13.097 em 2015 (BRASIL, 2015). Em 2015, foi aprovada a Emenda Constitucional EC-86/2015 (BRASIL, 2015), que reduziu as bases de financiamento do SUS, especificamente a parcela federal no financiamento, que passou a considerar a Receita Corrente Líquida (RCL) da União. Para Santos (2015): "O significado de cada um desses golpes no SUS e seu encadeamento nos 25 anos da sua existência é insofismável como grande indicador da política pública implícita (real), com lógica voltada para o mercado, fragmentação e iniquidade" (SANTOS, 2015, p. 586).

Assim, o SUS vem sendo objeto de ataques orquestrados pelos núcleos econômicos que comandam as políticas fiscal e monetária, para garantir o superávit primário que viabiliza o pagamento do mercado financeiro. O núcleo do Poder Executivo - Ministérios do Planejamento, da Fazenda e da Casa Civil - defende essa posição, consolidando a lógica neoliberal na política de saúde.

Além disso, o SUS, desde a sua criação, é alvo de disputas de interesses privatistas na área de saúde, ficando clara a luta de bastidores para garantir o acesso do setor privado ao fundo público. A Lei 8.080/1990 indicava em seu art. $4^{\mathrm{o}} \S$ 2º: "A iniciativa privada poderá participar do Sistema Único de Saúde - SUS, em caráter complementar” (BRASIL, 1990, não paginado). Entretanto, esse item vem sendo sistematicamente negado, na medida em que o Estado não ampliou os serviços e ações de saúde de acordo com as necessidades da população, levando à compra de serviços privados, principalmente de média e alta complexidade.

O governo Michel Temer, iniciado em 2016, com o impeachment da Presidenta Dilma Rousseff, impôs algumas decisões que aprofundam o caráter regressivo na saúde. Diante das filas e financiamento incipiente para garantir a resolutividade do SUS, o governo tenta vender a ideia de que o SUS é um sonho irrealizável, como afirmou o Ministro da Saúde Ricardo Barros.

O atual governo aposta na desconstrução do direito universal à saúde, consolidando a contrarreforma em curso na política de saúde. Aposta nas parcerias público-privadas, na execução das políticas e programas sociais, viabilizada através do acesso privado ao fundo público. Nesse sentido e respondendo a demandas das empresas de seguro de saúde, aprovou os planos acessíveis de saúde para a população de baixa renda. Flexibilizam-se as coberturas, reduzemse os serviços incluídos nesses planos, de forma a reduzir seu custo e seduzir a clientela de menor poder aquisitivo. Os planos acessíveis de saúde são voltados aos 77,32\% ${ }^{1}$ da população

${ }^{1}$ Consideramos, em janeiro de 2018, a estimativa de população do IBGE de 208.571.657 habitantes (INSTITUTO BRASILEIRO DE GEOGRAFIA E ESTATÍSTICA, [2017]) e a informação da Agência Nacional de Saúde Suplementar (ANS), referente a 2017, de 47.304.945 pessoas cobertas por planos de saúde (AGÊNCIA NACIONAL DE SAÚDE SUPLEMENTAR, [2018]).

Argum., Vitória, v. 10, n.1, p. 72-87, jan./abr. 2018. 
que utiliza o SUS para atender às necessidades de saúde, apontando, assim, para a ampliação da lucratividade do setor de seguros e também para a redução da clientela do SUS e, consequentemente, redução dos gastos estatais, liberando recursos para pagamento do superávit fiscal.

Mas a medida fundamental contra as políticas sociais, aí incluída a saúde, é a redução do financiamento de despesas primárias do Estado, com a aprovação da Emenda Constitucional 95, em 2016 (BRASIL, 2016), que define as regras para uso de recursos públicos em políticas sociais. Durante os próximos 20 anos, o gasto com saúde do ano subsequente será igual ao gasto do ano corrente, acrescido apenas da inflação pelo Índice Nacional de Preços ao Consumidor Amplo (IPCA).

Vieira e Benevides (2016) apontam os efeitos perversos dessa proposta. Haverá perdas significativas na área de saúde, com a desestruturação do SUS, já que: “[...] o gasto com saúde per capita do Brasil é um dos mais baixos entre países que possuem sistema universal de saúde e mesmo quando comparado ao de países vizinhos nos quais o direito à saúde não é um dever do Estado" (VIEIRA, BENEVIDES, 2016, p. 17). Vieira e Benevides (2016) projetam diferentes cenários de crescimento da economia, que mostram: quanto maior esse crescimento, menos recursos a área de saúde terá. As conclusões dos autores são preocupantes:

O congelamento do gasto federal com saúde provocará grandes dificuldades para o financiamento do SUS, pois estados e municípios não conseguirão absorver o impacto da perda de recursos. (VIEIRA; BENEVIDES, 2016, p. 18).

$[\ldots]$

A proposta de um avanço fiscal focado exclusivamente nas despesas primárias, por vinte anos, afeta particularmente as políticas sociais e desconsidera o efeito de tal medida para o desenvolvimento econômico e social do país nos médio e longo prazos (VIEIRA; BENEVIDES, 2016, p. 21).

Numa leitura dialética da Emenda Constitucional 95, a redução de recursos para a área de saúde será objeto de lutas dos trabalhadores no período em que vigorar, mas também de diferentes frações do capital que se apropriam do fundo público na área de saúde - empresas farmacêuticas, indústrias hospitalares, serviços de diagnóstico de média e alta complexidade. Que setores ficarão com mais recursos? Quem vai perder? Cidadãos e cidadãs que usam o SUS para responder às suas necessidades em saúde, como reagirão à desconstrução do SUS, quando tiverem que pagar um seguro privado limitado na assistência à saúde, enquanto seus direitos trabalhistas são reduzidos e eliminados?

Uma política universal, financiada por várias fontes, como previsto constitucionalmente, especialmente com recursos provenientes de impostos, tem um forte caráter progressivo quando as pessoas com maior renda pagam impostos mais altos. Quando a carga tributária recai em maior proporção sobre os mais pobres, deixando de taxar grandes fortunas, rendimentos e ganhos não decorrentes do trabalho, reduz-se esse efeito progressivo.

Ainda assim, o SUS representa uma possibilidade de garantir que o fundo público arque com serviços de saúde para todas as pessoas, principalmente as que dependem exclusivamente dos serviços públicos. No entanto, na medida em que o SUS trata os serviços privados não como complementares aos serviços públicos, mas garantindo que o fundo público seja acessível aos interesses privados, de forma ampla, seja através de pagamento de serviços de média e alta

Argum., Vitória, v. 10, n.1, p. 72-87, jan./abr. 2018. 
complexidade, seja através do gerenciamento de unidades de saúde, como Unidades de Pronto Atendimento (UPAS), de policlínicas, de hospitais, como os universitários e outros, esse gerenciamento privado do público significa que o Estado precisa despender mais recursos para pagamento dos serviços prestados pelos entes privados, em detrimento da ampliação e melhoramento dos próprios serviços. Estudo desenvolvido por Ximenes (2015) no estado de Pernambuco aponta que:

\begin{abstract}
A privatização do setor de saúde em Pernambuco, baseada no princípio da competição, representou o alastramento da ilusão de que, com a transferência da gestão das unidades hospitalares, os recursos públicos seriam melhor utilizados. Concluímos que o objetivo real da estratégia da terceirização, via modelo privatizante de gestão, é a apropriação do fundo público da saúde, o que sugere uma modalidade de privatização não-clássica, a partir da expansão do repasse dos recursos do fundo público da saúde para as OSs [organizações sociais] (XIMENES, 2015, p. 6).
\end{abstract}

O autor, após analisar os custos e a atuação de hospitais públicos gerenciados pela administração direta e por organizações sociais, apresenta-se extremamente crítico em relação à opção de utilização de organizações sociais e outros modelos de gestão apropriados da gestão privada, considerados eficientes e eficazes pelos adeptos da lógica neoliberal:

Nos dois modelos de gestão de unidades hospitalares, ocorreu um aumento do acesso dos usuários às unidades de saúde e enfatizamos que a totalidade dos atendimentos de alta complexidade ficou a cargo da administração pública direta. Além de não ter existido essa transferência [do fluxo de pacientes dos hospitais com gestão pública para os administrados pelas OSs], não ocorreu redução dos custos, que seria conseguida com a utilização desse modelo de gestão. Asseveramos que o custo por um atendimento de alta complexidade realizado pela OS foi três vezes superior ao custo de um atendimento realizado na gestão pública direta. Portanto, a adesão ao modelo para o gerenciamento de unidades de saúde teve como objetivo central a transferência e a apropriação de recursos e responsabilidades estatais. [...] Apenas uma OS (Fundação Martiniano Fernandes - Imip Hospitalar) se apropriou de 69,3\% dos recursos da saúde destinados para esse modelo. [...] Os hospitais com gestão direta do Estado se revelaram mais eficientes e eficazes que o modelo considerado 'inovador', pois realizaram muito mais atendimentos de alta complexidade, além de terem alocado menos recursos do fundo público da saúde (XIMENES, 2015, p. 163).

\title{
2 POLÍTICA DE SAÚDE PARA HIV
}

A partir dessas reflexões sobre o caráter potencialmente progressivo do SUS confrontado com as reformas regressivas implementadas ao longo das últimas décadas, pretendemos refletir sobre o enfrentamento da epidemia de HIV, tentando pensar sobre a assistência às pessoas vivendo com a infecção.

Nos anos 1980, com o surgimento da infecção por HIV, teve início uma mobilização pelo enfrentamento da doença que acometia principalmente homens que fazem sexo com homens, gays, travestis, pessoas usuárias de drogas injetáveis e pessoas com doenças que exigiam transfusões de sangue. No Brasil, essa mobilização levou à criação de programas de saúde em municípios com muitos casos de infecção e à aprovação da Lei 9.313 em 13 de novembro de 1996, que garante "[...] toda a medicação necessária a seu tratamento [...]" (BRASIL, 1996, não paginado) às pessoas com HIV e aids. Entre esses medicamentos incluem-se os antirretrovirais, que diminuem a vulnerabilidade a doenças correlacionadas à aids, reduzem a carga viral a

Argum., Vitória, v. 10, n.1, p. 72-87, jan./abr. 2018. 
níveis indetectáveis e inibem a transmissão do vírus a outras pessoas. Mas não somente esses medicamentos são necessários: quando ocorrem infecções correlacionadas, são necessários outros medicamentos, exames, internação, nem sempre disponíveis na rede do SUS dos municípios onde residem as pessoas necessitadas. Além disso, precisamos considerar os rumos da epidemia em nosso país e as novas diretrizes em relação ao HIV.

A princípio, vamos refletir sobre a atual dimensão do HIV e da aids no Brasil e seu enfrentamento. O Boletim Epidemiológico HIV Aids 2017 permite uma visualização da epidemia. De 1980 a junho de 2017 , foram identificados 882.810 casos de aids no país. Nos últimos cinco anos, foram registrados anualmente, em média, 40 mil novos casos de aids (BRASIL, 2017-a, p. 8). No Brasil, até 2014, o HIV não era de notificação compulsória, apenas os casos de aids, que representam as situações em que vírus já debilitou o organismo e a imunodeficiência permite o surgimento de doenças oportunistas.

O Relatório de Monitoramento Clínico do HIV do DIAHV/MS estima que, ao final de 2016, havia aproximadamente 830 mil pessoas vivendo com HIV, sendo que apenas 694 mil (84\%) estavam diagnosticadas; 655 mil destas (79\%) estavam vinculadas a algum serviço de saúde; e 563 mil (68\%) permaneciam vinculadas aos serviços. Entre as pessoas em atendimento, observa-se cobertura antirretroviral de $60 \%$ e supressão viral de $54 \%$ entre todos os indivíduos infectados pelo HIV. Identifica-se um crescimento do quantitativo de pessoas diagnosticadas, de 2012 para 2016, passando de 501.000 pessoas a 694.00o, enquanto a supressão viral passou de $37 \%$ dos casos em tratamento para $53 \%$ (BRASIL, 2017b, p. 19).

Quando calculadas as proporç̃oes em relação ao número de PVHIV, nota-se que as
mulheres apresentam resultados melhores do que os homens, em todas as etapas do
cuidado contínuo, com exceção da supressão viral - em que os valores encontrados
foram similares. Ressalta-se que a etapa do diagnóstico, mais precoce nas mulheres, é
a que causa essa superioridade nos indicadores para o sexo feminino. [...] Assim, o
acesso ao diagnóstico nelas é maior, mas a vinculação e retenção nos serviços, a reten-
ção em terapia e a supressão viral são inferiores (BRASIL, 2017b, p. 19).

Cresce, a cada ano, o total de pessoas iniciando tratamento antirretroviral. Só em 2016, foram iniciados 70 mil novos tratamentos, dos quais 68.000 entre pessoas com 18 anos ou mais (BRASIL, 2017-b, p. 61). Nesse ano, 498 mil pessoas encontravam-se em TARV - quase seis vezes mais que em 1999 (com 85 mil) (BRASIL, 2017b, p. 69).

De 2007 até junho de 2017, foram notificados 194.217 casos de infecção pelo HIV no Brasil (BRASIL, 2017a, p. 5). Entre os homens, nos últimos dez anos, tem ocorrido crescimento da aids, especialmente entre jovens de 15 a 19 anos. De 2006 para 2016, a taxa de detecção de aids quase triplicou, e, na faixa etária de 20 a 24 anos, a taxa mais que duplicou. Apesar desses aumentos, a maior taxa de detecção de aids em 2016 ocorreu entre os indivíduos na faixa etária de 35 a 39 anos: 49,4 casos/100.00o habitantes, 21,5\% menor do que a observada em 2006, conforme mostra o Gráfico 1 (BRASIL, 2017a, p. 12). Também houve crescimento na detecção de aids, na faixa etária de 60 anos ou mais.

Gráfico 1. Taxa de detecção de aids (/10o mil hab.) em homens, segundo faixa etária e sexo, Brasil. 2006 e 2016. 


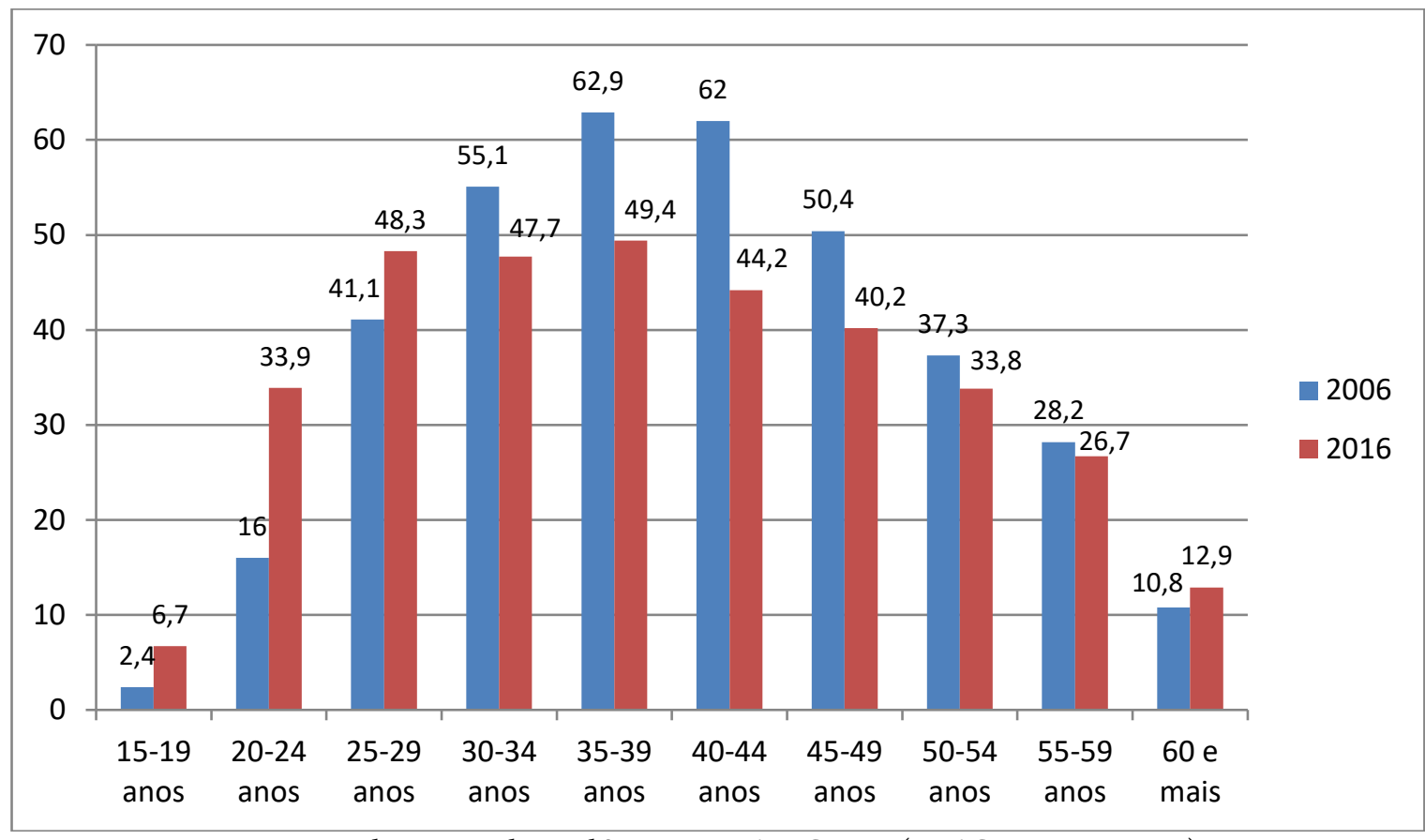

Fonte: Boletim Epidemiológico HIV AIDS 2017 (BRASIL, 2017a, p. 12).

No ano de 2016, foram notificados 37.884 casos de infecção pelo HIV, distribuídos regionalmente: $3.912(10,3 \%)$ casos na região Norte, $7.693(20,3 \%)$ casos na região Nordeste, 15.759 $(41,6 \%)$ na região Sudeste, $7.688(20,3 \%)$ na região Sul e $2.832(7,5 \%)$ na região Centro-Oeste (BRASIL, 2017a, p. 5). O Sudeste lidera os casos de infecção por HIV, enquanto o Centro-Oeste é menos atingido.

No período de 2007 a 2017, a maioria dos casos de infecção pelo HIV encontra-se nas faixas de 20 a 34 anos, 52,5\% do total (BRASIL, 2017a, p. 5). Entre pessoas brancas, ocorreram 47,6\% de casos e $51,5 \%$ entre pretos e pardos. Entre as mulheres, $43,2 \%$ dos casos são entre brancas e $55,9 \%$ entre pretas e pardas, o que sugere seu crescimento entre pessoas de menor renda no país, as de origem negra.

Considerando a categoria de exposição, entre os homens, 48,9\% dos casos foram decorrentes de exposição homossexual, 37,6\% heterossexual, 9,6\% bissexual e 2,9\% se deram entre usuários de drogas injetáveis (UDI). Entre as mulheres, 96,8\% dos casos se inserem na categoria de exposição heterossexual (BRASIL, 2017a, p. 5).

Em relação à aids, o Boletim Epidemiológico identifica uma tendência de queda na taxa de detecção no país, capitaneada pelas regiões Sudeste e Sul, ainda que no Nordeste e no Norte haja uma tendência linear de crescimento da taxa de detecção, como pode ser visto na Tabela 1 (BRASIL, 2017a, p. 8). O crescimento da aids nas regiões mais pobres do país, com menor infraestrutura de serviços de saúde, emite um alerta para o enfrentamento da aids.

Tabela 1. Taxa de detecção de aids no Brasil, por regiões, 2006 e 2016.

\begin{tabular}{l|l|l}
\hline Região & 2006 & 2016 \\
Brasil & 19,9 & 18,5 \\
Norte & 14,9 & 24,8 \\
Nordeste & 11,2 & 15,2 \\
Centro-Oeste & - & 16,7 \\
\hline
\end{tabular}

Argum., Vitória, v. 10, n.1, p. 72-87, jan./abr. 2018. 


\begin{tabular}{l|l|l}
\hline Sudeste & 23,5 & 17,3 \\
Sul & 30,2 & 25,3 \\
\hline \multicolumn{2}{l}{ Fonte: Boletim Epidemiológico HIV AIDS 2017 (BRASIL 2017a, p.8). }
\end{tabular}

Fonte: Boletim Epidemiológico HIV AIDS 2017 (BRASIL, 2017a, p.8).

A taxa de detecção de aids em menores de cinco anos, indicador proxy para o monitoramento da transmissão vertical do HIV, apresenta tendência de queda nos últimos dez anos, de 3,6 casos/10o.ooo habitantes em 2006 para 2,4 casos/100.ooo habitantes em 2016, correspondendo a uma queda de $34 \%$. Apenas a região Nordeste apresentou um leve aumento na taxa de detecção de aids em menores de cinco anos: 8,7\%, passando de 2,3 casos por 100 mil habitantes em 2006 para 2,5 casos por 100 mil habitantes em 2016 (BRASIL, 2017-a, p. 13). Novamente na região mais pobre, registra-se aumento de transmissão de mãe para filho, o que indica fragilização ou insuficiência de atenção a gestantes.

Desde 1980 até junho de 2017, 65\% dos casos de aids ocorreram entre homens e 34,7\% em mulheres (BRASIL, 2017-a, p.10). Entretanto, a razão de sexos tem diferenças regionais: proporcionalmente há mais mulheres afetadas pela aids na região Sul que homens, enquanto no Centro-Oeste há mais homens que mulheres afetadas. Na região Nordeste, de 2015 para 2016, caiu a razão de sexo, indicando um crescimento dos casos de aids entre mulheres (BRASIL, 2017-a, p. 11).

Tabela 2. Razão de sexo para casos de aids, Brasil, 2016.

\begin{tabular}{l|l}
\hline Região & Casos de aids em homens para cada 10 \\
& mulheres \\
Norte & 22 \\
Nordeste & 21 \\
Centro-Oeste & 26 \\
Sudeste & 25 \\
Sul & 17 \\
\hline \multicolumn{2}{l}{ Boletim Epidemiológico HIV AIDS 2017 (BRASIL, 2017a, p. 11) }
\end{tabular}

E a mortalidade por aids? Considerando o período entre 2006 e 2016, a queda no coeficiente de mortalidade padronizado para o Brasil foi de $11,9 \%$. Entretanto, nas regiões Norte e Nordeste, os coeficientes sofreram aumento de 7,6\% e 2,3\%, acompanhando a tendência de crescimento da aids nessas regiões (BRASIL, 2017a, p. 16).

Internacionalmente, o Programa Conjunto das Nações Unidas sobre HIV/AIDS (2013), conhecido pela sigla em inglês Unaids, vem indicando desde 2014 a estratégia conhecida como 9o90-90, tendo como meta o fim da epidemia até 2030: que 90\% das pessoas com HIV conheçam seu diagnóstico, $90 \%$ dessas pessoas estejam em tratamento com antirretrovirais e que, destas pessoas, $90 \%$ estejam com carga indetectável do vírus. É necessário, portanto, garantir o acesso ao tratamento com antirretrovirais (TARV) a partir do momento de detecção do vírus. Portanto, o enfrentamento do HIV, atualmente, exige um conjunto de ações. Fala-se em Mandala de Prevenção Combinada do HIV, envolvendo: testagem regular para HIV; exame do HIV no pré-natal (para evitar a transmissão vertical, da mãe para o bebê); distribuição de preservativos masculinos e femininos, e gel lubrificante; redução de danos para usuários de drogas; garantia de acesso aos serviços de saúde; uso de circuncisão; tratamento de outras infecções sexualmente transmissíveis; profilaxia pós-exposição ao HIV (PeP); profilaxia pré-exposição 
(PrEP); tratamento com antirretrovirais; e, tão importante quanto as medidas indicadas, a diminuição do estigma e preconceito e o trabalho de conteúdos subjetivos das pessoas.

Para responder a essas demandas, o SUS oferece uma rede de serviços, distribuída pelo território nacional, com parcerias entre diferentes níveis de governo. De acordo com o Ministério da Saúde, em 2016, havia 443 Centros de Testagem e Aconselhamento (CTA) e 654 Serviços de Assistência Especializada (SAE). Compõem a rede de serviços os Hospitais-Dia (HD), no total de 77 até 2013, e a Assistência Domiciliar Terapêutica (ADT), além de hospitais especializados em doenças infectocontagiosas.

Villarinho et al. (2013) consideram que, apesar desses serviços, o cuidado com as pessoas com HIV tem grandes desafios a superar, pois “[...] a estruturação de uma rede assistencial em HIV contemplando majoritariamente ações de média e alta complexidade não tem sido suficiente para garantir a integralidade da atenção à saúde" (VILLARINHO et al., 2013, p. 276).

Duas novas medidas vão ampliar os gastos com antirretrovirais: o Ministro da Saúde, no $11^{\mathbf{0}}$ Congresso de HIV e $4^{\circ}$ Congresso de Hepatites Virais, realizado em Curitiba, em 2017, informou que, a partir de 2018, todas as pessoas que vivem com HIV e aids no país terão acesso ao Dolutegravir, medicamento mais moderno e eficaz (BRASIL, 2017c), e o Ministério da Saúde tem orçamento de R\$ 1,1 bilhão para compra. Outra mudança a ser introduzida no enfrentamento do HIV é o Protocolo Clínico e Diretrizes Terapêuticas para Profilaxia Pré-Exposição (PrEP) de risco à infecção pelo HIV. O PrEP objetiva reduzir o risco da infecção pelo HIV antes da exposição, por meio da utilização de antirretrovirais em pessoas não infectadas e que mantêm relações de risco com maior frequência: homens que fazem sexo com homens, gays, travestis, transexuais, profissionais do sexo e casais soro diferentes. O Brasil será o primeiro país na América Latina a ofertar a PrEP com implementação gradual, a partir de dezembro de 2017, inicialmente em 23 cidades, três das quais na região Nordeste: Salvador, Fortaleza e Recife.

As organizações da sociedade civil, de apoio às pessoas com HIV, entendem que ações de prevenção, de informação para a população em geral e as populações-chave - homens que fazem sexo com homens, travestis, profissionais do sexo, usuários de drogas injetáveis - têm ficado em segundo plano, recebido menos recursos e incentivo. Richard Parker (2015), da Associação Brasileira Interdisciplinar de Aids (ABIA), critica a redução de gastos públicos gerada pela proposta neoliberal, que retira recursos para ações de prevenção, para o monitoramento das ações, e focaliza os gastos no uso de respostas biomédicas à aids. Considera prioritário testar e tratar imediatamente as pessoas infectadas para que diminuam a morbidade e a mortalidade e seja reduzida a transmissão do HIV, mas sem restringir o trabalho preventivo.

Os cortes de gastos sociais aprovados pela Emenda Constitucional 95 (BRASIL, 2016), que limitam o orçamento das políticas sociais pelos próximos 20 anos, assim como as restrições de contratação, devido à Lei de Responsabilidade Fiscal, vão trazer dilemas ao SUS e ao tratamento do HIV. Esses cortes vão repercutir na vida de quem vive com HIV, como na de todas as pessoas que usam o SUS. Provavelmente não faltarão antirretrovirais, garantidos por lei. Mas talvez não cheguem a todos os cantos do país, com a tendência de redução do SUS. Além disso, as pessoas que vivem com HIV precisam não só desses medicamentos específicos, mas de tratamento para doenças oportunistas, internação, exames de média e alta complexidade, acompanhamento contínuo, e a redução de recursos para o SUS irá afetá-las. Se tiverem que pagar por serviços de saúde, cristalizar-se-á a mais perversa regressividade. A Organização

Argum., Vitória, v. 10, n.1, p. 72-87, jan./abr. 2018. 
Mundial de Saúde (OMS), em documento de 2010, reafirma o caráter regressivo dos pagamentos diretos de serviços de saúde, inclusive destacando que o caráter desigual extrapola a questão socioeconômica, incidindo também sobre as mulheres, ou seja, sobre pessoas que sofrem preconceitos e discriminação, como também os negros.

Os pagamentos diretos têm sérias repercussões sobre a saúde. Obrigar as pessoas a pagar no momento e local da prestação de serviços desencoraja-as de utilizar os serviços (particularmente os de promoção da saúde e prevenção da doença), e encoraja-os a protelar rastreios de saúde. Isto significa que elas não recebem tratamento nas etapas mais precoces das doenças, quando as probabilidades de cura são maiores (ORGANIZAÇÃO MUNDIAL DE SAÚDE, 2010, p. 5).

Os pagamentos diretos são a forma menos equitativa de financiamento do sector da saúde. Têm natureza regressiva, permitindo que os mais ricos paguem o mesmo que os pobres por um determinado serviço. O enquadramento socioeconômico não é a única base da desigualdade. Em culturas onde a mulher tem um estatuto inferior ao homem, as mulheres e crianças das famílias são, muitas vezes, preteridas em relação aos homens quando são cobradas taxas de utilização e, por isso, têm menos probabilidade de aceder aos serviços de saúde (ORGANIZAÇÃO MUNDIAL DE SAÚDE, 2010, p. 45).

A alternativa que vem sendo desenvolvida pelo Ministério da Saúde, os planos acessíveis de saúde, provavelmente não será viável para as pessoas com HIV, que têm grandes dificuldades de inserção no mercado de trabalho, enfrentando preconceitos e restrições e, portanto, terão menos condições de pagar por serviços de saúde. Os planos de menor custo não terão cobertura para internação, e os planos que contemplam essa modalidade podem ter coparticipação dos usuários. O HIV, como mostram os dados, tem crescido nas regiões Nordeste e Norte, atingindo mais as pessoas negras e pardas. No Nordeste, ainda cresce entre mulheres, reconhecidamente em desvantagem na questão trabalho, com remuneração quase sempre inferior aos homens que realizam as mesmas tarefas.

Esses destaques indicam o potencial regressivo das atuais reformas na política de saúde, que se estenderão ao enfrentamento do HIV. Apesar de a carga tributária ser proporcionalmente maior para as pessoas de menor renda, o que significa que contribuem mais, proporcionalmente, para o fundo público, estas vão se deparar com redução de serviços diante dos cortes orçamentários. Serão instadas a adquirir um plano acessível de saúde, que não dará conta de suas necessidades, sem ter como pagar por ele. Terão que permanecer no SUS, cada vez mais sucateado e limitado em sua oferta de atenção à saúde. Como garantir todas as ações da Mandala de Prevenção Combinada do HIV, com os cortes previstos? Provavelmente o tratamento biomédico do HIV, concentrado nos antirretrovirais, vai se consolidar, inclusive por pressão da indústria de medicamentos, e pelas pressões internacionais para reduzir/acabar com a transmissão do HIV. Se voltarmos os olhos para as regiões mais pobres do país, para as mulheres, para as pessoas negras, para a fragilidade das ações preventivas, para as populaçõeschave, veremos que a regressividade das reformas atinge diretamente nosso país. É preciso reafirmar que:

A tarefa primordial para debater políticas de saúde é retomar o fio da meada, as críticas à medicalização da vida e a imposição de padrões excludentes de consumo de tecnologias, movidos pela mercantilização do processo saúde-doença. O direito constitucional à saúde não se limita ao acesso a ações assistenciais; estende-se para a proteção

Argum., Vitória, v. 10, n.1, p. 72-87, jan./abr. 2018. 
contra os riscos, especialmente os sociais. Uma agenda de políticas de saúde deve ser construída em conjunto com as políticas para as cidades - transporte, segurança, trabalho e renda - e dialogar com as políticas de reconhecimento de gênero, raça-cor e identidades étnicas (BAHIA, 2016, p. 55-56).

Essa, no entanto, não é a agenda no momento, conforme (OCKÉ-REIS, 2016) aponta. O pensamento hegemônico, fortalecido no governo Temer, aponta para o fim do SUS e a privatização do sistema de saúde. Como barrar esse processo, fortalecendo as políticas sociais é a questão que deve orientar as lutas sociais pelo direito à vida.

A política de saúde para HIV compõe a política de saúde brasileira, sofrendo como ela, as consequências da regressividade da constituição do fundo público, que financia as ações do Estado. Na medida em que o sistema tributário brasileiro é injusto, a taxação de consumo onera os mais pobres, tornando-os aqueles que proporcionalmente mais contribuem para a formação do fundo público, e se ressentem mais quando o Estado não garante a concretização das políticas públicas, como a saúde. Como afirma Salvador:

As alterações na legislação infraconstitucional, realizadas a partir de 1995, enfraqueceram os princípios básicos do sistema tributário da Constituição de 1988, agravando as distorções e, sobretudo, aprofundando a regressividade do sistema. As modificações, que usaram leis ordinárias e regulamentos transferiram o ônus para a renda do trabalho e a população mais pobre, alterando o perfil da arrecadação (SALVADOR, 2016, p. 61).

O financiamento, além de ser custeado através desse sistema regressivo, vem sendo sistematicamente alvo de cortes e sujeito a constrangimentos, expostos por Santos (2015), reduzindo a capacidade resolutiva, gerando filas, mau atendimento, aumentando o sofrimento das pessoas com problemas de saúde, além de reduzir a ação preventiva. Notícia veiculada no UOL (RODRIGUES, 2018) é um exemplo, em meio ao surto de febre amarela, com mortes, no país: "Os gastos no combate preventivo a doenças transmitidas por mosquitos caíram em São Paulo no último ano, às vésperas do avanço da febre amarela em cidades paulistas" (RODRIGUES, 2018, não paginado).

A adoção de gerenciamento de unidades de saúde por organizações sociais privadas, sob a justificativa de eficiência e eficácia, significa mais gastos para a administração pública, como aponta Ximenes (2015), quando recursos que poderiam ser dirigidos para atividades-fim voltam-se para pagamento de atividades-meio.

O controle da aids era considerado, em 2015, por Santos, como privilegiado no SUS, assim como as áreas de saúde mental, saúde do trabalhador, urgência/emergência, transplantes, hemocentros, vigilância em saúde: "Vejo-os como pontes voltadas para o futuro. Ao mesmo tempo em que demonstram irreversibilidade, nossos nichos e trincheiras, não conseguem sair da exceção para a regra no volume de atendimento, no financiamento, no modelo de atenção e qualidade" (SANTOS, 2015, p. 583).

Na avaliação de Santos (2015), diante do aprofundamento da perspectiva neoliberal, do crescimento do conservadorismo e do fortalecimento dos interesses privatistas, a política de saúde mostra-se fragilizada, pois, mesmo as áreas de excelência no SUS vêm sendo tomadas de

Argum., Vitória, v. 10, n.1, p. 72-87, jan./abr. 2018. 
assalto pela redução dos gastos sociais, para favorecimento do ajuste fiscal e pagamento de juros da dívida pública.

Ainda que se amplie o gasto com antirretrovirais, em resposta aos direcionamentos do Unaids, sua distribuição, as ações preventivas e o acesso aos serviços de saúde se veem fundamentalmente comprometidos a partir do Governo Temer, pelos próximos 20 anos, desde a Emenda Constitucional 95.

\section{CONSIDERAÇÕES FINAIS}

O caráter universal da política de saúde brasileira, como dever do Estado, vem sendo cerceado pela regressividade do sistema tributário, pela redução do financiamento, pelos cortes nas políticas públicas, aprofundados a partir do Governo Temer. A saúde vem sendo espaço privilegiado de mercadorização e lucratividade dos interesses privados, levando à proposição de planos acessíveis de saúde, traduzindo a ideia de que o acesso aos serviços de saúde, mesmo aos mais básicos e essenciais, devem ser pagos. Os cidadãos já contribuem para o fundo público através da taxação do consumo e, além disso, serão estimulados falaciosamente a pagar por serviços de saúde, o que potencializa a regressividade na política de saúde.

A epidemia de HIV em nosso país mostra-se, em tese, sob controle, apesar de ainda crescer entre homens jovens, entre as mulheres no Nordeste, de haver aumento da mortalidade, especialmente entre mulheres negras. Diante do quadro de redução dos recursos para os próximos 20 anos, a tendência é de imposição de limites sobre a política para HIV, ainda que se garantam os antirretrovirais. Mas o enfrentamento do HIV exige muito mais que isso, inclusive diante da dificuldade de utilização de medicamentos de uso contínuo, por toda a vida. $\mathrm{O}$ caráter regressivo que recai sobre essa política é uma marca da negação do direito à saúde nestes tempos.

\section{REFERÊNCIAS}

AGÊNCIA nacional de saúde suplementar. Sala de situação. Rio de Janeiro, [2018]. Disponível em: <http://www.ans.gov.br/perfil-do-setor/dados-e-indicadores-do-setor/sala-de-situacao $>$. Acesso em: 30 jan. 2018.

BAHIA, L. Políticas de saúde no Brasil: notas para o debate de alternativas. PolitiKa, Brasília (DF), v. 1, n. 3, p. 48-57, jan./jun. 2016. Disponível em: <https://issuu.com/fjmangabeira/docs/revista-politika-3-portugues>. Acesso em: 16 out. 2017.

BRASIL. Presidência da República. Lei no 8.080, de 19 de setembro de 199o. Dispõe sobre as condições para promoção, proteção e recuperação da saúde, a organização e o funcionamento dos serviços correspondentes e dá outras providências. Brasília (DF), 1990. Disponível em: <http://www2.camara.leg.br/legin/fed/lei/199o/lei-8o8o-19-setembro1990-365093-normaatualizada-pl.pdf>. Acesso em: 1o fev. 2018.

BRASIL. Presidência da República. Lei no 9.313, de 13 de novembro de 1996. Dispõe sobre a distribuição gratuita de medicamentos aos portadores do HIV e doentes de AIDS. 
Brasília (DF), 1996. Disponível em: <http://www.planalto.gov.br/ccivil_03/leis/L9313.htm>. Acesso em: 26 dez. 2017.

BRASIL. Presidência da República. Emenda Constitucional no 29, de 13 de setembro de 200o. Altera os arts. 34, 35, 156, 160, 167 e 198 da Constituição Federal e acrescenta artigo ao Ato das Disposições Constitucionais Transitórias, para assegurar os recursos mínimos para o financiamento das ações e serviços públicos de saúde. Brasília (DF), 200o. Disponível em: <http://www.planalto.gov.br/ccivil_03/constituicao/emendas/emc/emc29.htm>. Acesso em: 20 mar. 2018.

BRASIL. Câmara dos Deputados. Medida Provisória no 656/2014. Reduz a zero as alíquotas da Contribuição para o PIS/PASEP, da COFINS, da Contribuição para o PIS/PasepImportação e da Cofins-Importação incidentes sobre a receita de vendas e na importação de partes utilizadas em aerogeradores, prorroga benefícios, altera o art. 46 da Lei $\mathbf{n}^{\circ}$ 12.715, de 17 de setembro de 2012, que dispõe sobre a devolução ao exterior ou a destruição de mercadoria estrangeira cuja importação não seja autorizada, e dá outras providências. Brasília (DF), 2014. Disponível em: <http://www.camara.gov.br/proposicoesWeb/fichadetramitacao?idProposicao=622854>. Acesso em: 20 mar. 2018.

BRASIL. Presidência da República. Lei no 13.097 , de 19 de janeiro de 2015. Reduz a zero as alíquotas da Contribuição para o PIS/PASEP, da COFINS, da Contribuição para o PIS/PasepImportação e da Cofins-Importação incidentes sobre a receita de vendas e na importação de partes utilizadas em aerogeradores; prorroga os benefícios previstos nas Leis nos 9.250, de 26 de dezembro de 1995, [...] e do Decreto-Lei no 3.365, de 21 de junho de 1941; e dá outras providências. Brasília (DF), 2015. Disponível em: <http://www2.camara.leg.br/legin/fed/lei/2015/lei-13097-19-janeiro-2015-780071-publicacaooriginal-145954-pl.html>. Acesso em: 20 mar. 2018.

BRASIL. Presidência da República. Emenda Constitucional no 86, de 17 de março de 2015. Altera os arts. 165, 166 e 198 da Constituição Federal, para tornar obrigatória a execução da programação orçamentária que especifica. Brasília (DF), 2015. Disponível em: <http://www.planalto.gov.br/ccivil_03/constituicao/emendas/emc/emc86.htm>. Acesso em: 20 mar. 2018.

BRASIL. Presidência da República. Emenda Constitucional no 95, de 15 de dezembro de 2016. Brasília (DF), 2016. Disponível em: <http://www.planalto.gov.br/ccivil_o3/constituicao/emendas/emc/emc95.htm>. Acesso em: 1o fev. 2018.

BRASIL. Ministério da Saúde. Boletim Epidemiológico HIV/AIDS 2017. Brasília (DF), 2017-a. Disponível em: <http://www.aids.gov.br/pt-br/pub/2017/boletim-epidemiologicohivaids-2017>. Acesso em: 26 dez. 2017.

BRASIL. Ministério da Saúde. Relatório de monitoramento clínico do HIV. Brasília (DF), 2017-b. Disponível em: <http://www.aids.gov.br/pt-br/pub/2017/relatorio-de-monitoramento-clinico-do-hiv>. Acesso em: 18 jan. 2018.

BRASIL. Ministério da Saúde. Ministério da Saúde amplia oferta do tratamento para aids com medicamento inovador. Notícias, Brasília (DF), 2017-c. Disponível em: 
<http://www.aids.gov.br/pt-br/noticias/ministerio-da-saude-amplia-oferta-do-tratamentopara-aids-com-medicamento-inovador>. Acesso em: 2 out. 2017.

INSTITUTO BRASILEIRO DE GEOGRAFIA E ESTATÍSTICA. Estimativa de população 2017. Brasília (DF), 2017. Disponível em: <https://www.ibge.gov.br/estatisticas-novopor$\mathrm{tal} /$ sociais/populacao/9103-estimativas-de-populacao.html?edicao $=16985 \& \mathrm{t}=$ destaques $>$. Acesso em: 30 jan. 2018.

OCKÉ-REIS, C. É fundamental entender a política de saúde como capaz de reduzir os efeitos da crise e de induzir o crescimento. Centro de Estudos Estratégicos da Fiocruz, 19 set. 2016. Entrevista reproduzida pelo HUmanizaSUS. Rio de Janeiro, 2016. Disponível em: <http://www.cee.fiocruz.br/?q=node/455>. Acesso em: 24 nov. 2017.

ORGANIZAÇÃO mundial de saúde. Relatório Mundial da Saúde: financiamento dos sistemas de saúde: o caminho para a cobertura universal. Genève, 2010. Disponível em: <http://www.who.int/whr/2010/whr10_pt.pdf>. Acesso em: 31 jan. 2018.

PARKER, R. O fim da aids?. Rio de Janeiro: Associação Brasileira Interdisciplinar de Aids (ABIA), 2015. Disponível em: <http://abiaids.org.br/wp-content/uploads/2015/11/FIM_da_AIDS_capaverm_jan2016.pdf $>$. Acesso em: 16 out. 2017.

PROGRAMA CONJUNTO DAS NAÇÕES UNIDAS SOBRE HIV/AIDS. 90-9o-9o: uma meta ambiciosa de tratamento para contribuir para o fim da epidemia de AIDS. Genève: UNAIDS, 2013. Disponível em: <https://unaids.org.br/wp-content/uplo-

ads/2015/11/2015_11_20_UNAIDS_TRATAMENTO_META_PT_v4_GB.pdf $>$. Acesso em: $\mathbf{1}^{\circ} \mathrm{fev}$. 2018.

RODRIGUES, A. Alckmin e Doria cortam gastos em ações de combate a mosquitos. Folha de São Paulo, São Paulo, 2 fev. 2018. Disponível em: <https://www1.folha.uol.com.br/cotidiano/2018/o2/alckmin-e-doria-cortam-gastos-em-acoes-de-combate-a-mosquitos.shtml>. Acesso em: 2 fev. 2018.

SALVADOR, E. O injusto sistema tributário brasileiro. Revista PolitiKa, Brasília (DF), v. 1, n. 3, p. 58-69, jan./jun. 2016. Disponível em: <https://issuu.com/fjmangabeira/docs/revistapolitika-3-portugues>. Acesso em: 16 out. 2017. 58-69

SANTOS, N. SUS fora dos rumos: busca de luzes: acima do SUS. Saúde em Debate, Rio de Janeiro, v. 39, n. 106, p. 582-60o, jul./set. 2015. Disponível em: <http://www.scielo.br/pdf/sdeb/v39n106/o103-1104-sdeb-39-106-00582.pdf>. Acesso em: 16 out. 2017.

VIEIRA, F.; BENEVIDES, R. Os impactos do novo regime fiscal para o financiamento do Sistema Único de Saúde e para efetivação do direito à saúde no Brasil. Brasília (DF): IPEA, set. 2016. (Nota Técnica IPEA, n. 28). Disponível em: <http://www.ipea.gov.br/portal/images/stories/PDFs/nota_tecnica/160920_nt_28_disoc.pdf>. Acesso em: 16 out. 2017.

VILLARINHO, M. et al. Políticas públicas de saúde face à epidemia da AIDS e a assistência às pessoas com a doença. Revista Brasileira de Enfermagem, Brasília (DF), v. 66, n. 2,

Argum., Vitória, v. 10, n.1, p. 72-87, jan./abr. 2018. 
mar./abr. 2013. Disponível em: <http://www.scielo.br/scielo.php?script=sci_arttext\&pid=So034-71672013000200018>. Acesso em: 26 dez. 2017.

XIMENES, A. A apropriação do fundo público da saúde pelas Organizações Sociais em Pernambuco. 2015. 195f. Tese (Doutorado em Serviço Social)-Programa de Pós-Graduação em Serviço Social da Universidade Federal de Pernambuco, Recife, 2015. Disponível em: < https://repositorio.ufpe.br/handle/123456789/16557>. Acesso em: 16 out. 2017.

\section{Ana Cristina de Souza VIEIRA}

Doutora em Serviço Social pela Pontifícia Universidade Católica de São Paulo (PUCSP). Professora Titular da Graduação e Pós-Graduação em Serviço Social da Universidade Federal de Pernambuco (UFPE). Pesquisadora ${ }_{1 B}$ do Conselho Nacional de Desenvolvimento Científico e Tecnológico. 